\title{
A social work study on emotional intelligence among different groups of people how are addicted to drugs
}

\author{
Mohammad Reza Iravani $^{a^{*}}$ and Seyed Esmael Mosavi ${ }^{\mathbf{b}}$
}

${ }^{a}$ Department of Social Work, Islamic Azad University of Khomeinishahr, Khomeinishahr Branch, Daneshjou Blvd, Iran

${ }^{b}$ Department of Guidance \&Counseling, Islamic Azad University of Khomeinishahr, Khomeinishahr Branch, Daneshjou Blvd, Iran

\begin{tabular}{l}
\hline A R T I C L E I N F O \\
\hline Article history: \\
Received September 10, 2011 \\
Received in Revised form \\
September, 12, 2011 \\
Accepted 15 September 2011 \\
Available online \\
22 September 2011 \\
\hline Keywords: \\
Emotional intelligence \\
Social work study \\
Drug addiction \\
Drug addiction recovery
\end{tabular}

$$
\text { A B S T R A C T }
$$

\begin{abstract}
Drug addiction has become serious problem among many developing countries. Many young people become addicted to different toxicated materials and, as a result, they cannot contribute to their society. They lose any employment opportunity, cannot continue their education and lose their healthcare. In this paper, we present an empirical study to measure emotional intelligence among different groups of people who were addicted to drugs. The study distributes a questionnaire among three groups consists of 117 questions and 15 scales. The first group of the survey is under community-based treatment, the second group includes the people who are members of a community with unknown identification and the third group covers outpatient patient who receive medication. The results of our survey indicate the level of emotional intelligence among the first group of our study is much more than the other groups.
\end{abstract}

(c) 2012 Growing Science Ltd. All rights reserved.

\section{Introduction}

Addiction is one of the most important issues threatening young people in developing countries specially those who live in Middle East countries. Unfortunately, there are countries who are victims of drug solely because of geographical position they have and there is a strong need to perform social studies to find the effects of different issues on addiction. One of the primary issues in such studies is to learn the effect of emotional intelligence (EI) on drug addiction. During the past few decades, there are enormous studies on this kind of investigation (Matthews et al., 2006; Williams et al., 2009; de Sousa Uva et al., 2010; Côté et al., 2010.; Kilduff et al., 2010; Joseph \& Newman, 2010; Schutte \& Malouff, 2011). Besharat (2007) presented psychometric properties of Farsi version of the EI Scale41.

Song et al. (2010) investigated the differential effects of general mental ability and emotional intelligence on academic performance and social interactions. They considered the debate about whether EI had incremental validity over and above traditional intelligence dimensions and proposed that EI and general mental abilities (GMA) differ in predicting academic performance and the quality

* Corresponding author. Tel: + 989131943910

E-mail addresses: iravani@iaukhsh.ac.ir (M. R. Iravani) 
of social interactions among college students. Using two university student samples, they reported some support for the notion that EI and GMA each had a unique power to predict academic performance, and that GMA was the stronger predictor.

Trinidad and Johnson (2002) investigated the relationship between emotional intelligence and early addiction in tobacco and alcohol. They reported that the adolescents with high EI could possess a greater mental ability to read others well and detect unwanted peer pressure.

Khanmohammadi et al. (2009) reported that applying of some plans in the field of increasing emotional intelligence could help people with positive attitudes to addiction to manage the bad problems and event and as a result reduce tendency to addiction. Talebzadeh and Homayouni (2010) performed a survey on relationship between emotional intelligence and personality traits in addicted people. The results of their survey indicated that high emotional intelligence was related positive and significant with extroversion, openness to experience and Conscientiousness. They also recommended to set the programs for enhancing the EI to increase mental health, life satisfaction and social skills to have personality and psychological health and prevent tendency to abnormal behavior specially tendency to addiction.

Hill and Maggi (2011) investigated the relationship between EI and drug addiction among Canadian youth. They measured emotional intelligence with a short-form of the original EQ-i (), which evaluated overall emotional intelligence and five dimensions: interpersonal competencies, intrapersonal competencies, stress management competencies, adaptability competencies and general mood. They divided their participants into three groups of daily, occasional or non-smokers and performed multinomial logistic regression analyses to examine the association between emotional intelligence with daily and occasional smoking. Their results suggested that emotional intelligence could comprise gender-specific protective and risk factors for occasional and daily smoking, which in turn is in the development of smoking prevention programs.

There are also new generations of drug addiction such as addiction to internet, playing games, talking with mobile phones, etc. Beranuy et al. (2009) investigated internet and mobile phone addiction and clinical symptoms in college students by investigating EI effects. Parker et al. (2008) studied the relationship between EI among those people who aggressively use internet or mobile services.

Khatiri Yanesari et al. (2010) investigated whether EI could prevent addiction to internet. They showed that there was negative significant correlation between components of EI including appraisal of emotion, utilization of emotion and general score of emotional intelligence. They reported that higher levels of emotional intelligence associated with lower levels of addiction to internet.

The proposed study of this paper investigates the impact of EI on different groups addicted to drugs using some statistical methods. The organization of this paper first explains details of our study in section 2. Section 3 is devoted to the results of our survey. Finally, concluding remarks are given in the last to summarize the contribution of the paper.

\section{Problem statement}

The proposed study of this paper attempts to realize whether different treatment program has any effect on people's EI. The program selects three groups of people who receive medication to get rid of drug addiction. The first group includes those from community-based treatment (CBT), the second group includes the people who are members of a community with unknown identification (UI) and the third group covers outpatient patient (OP) who receive medication.

We have adopted standard EI questionnaire which was examined on 3831 people from 6 different nationalities and the results was believed to be valid. We have examined the results through three levels of verification tests. In the first level, we consulted details of our questions with some experts 
and received their opinions. In the second run, we performed some preliminary tests on the questionnaire and after some validation test; the questionnaires were distributed among people who participated in our survey. We have chosen three groups with equal size of 50 people from each group.

\section{The results}

The main hypothesis of this paper examines whether there is a meaningful difference on average EI among three groups of participants in our survey. Table 1 shows details of our survey for our survey on the main question. As we can observe from the results of Table 1, the people who were enrolled in community-based treatment maintained an average of 318.52 , which is well more than the other average numbers we get from the people who participated in other groups. Now we have to see whether there is a meaningful difference between the average numbers of these three groups or not.

Table 1

The results of the survey on the main question

\begin{tabular}{|c|c|c|c|c|c|c|c|c|}
\hline \multirow[b]{2}{*}{ Group } & \multirow[b]{2}{*}{ Size } & \multicolumn{7}{|c|}{$95 \%$ confidence interval } \\
\hline & & Mean & $\begin{array}{r}\text { Standard } \\
\text { deviation }\end{array}$ & Error & $\begin{array}{l}\text { Lower } \\
\text { bound }\end{array}$ & $\begin{array}{l}\text { Upper } \\
\text { bound }\end{array}$ & Minimum & Maximum \\
\hline UI & 59 & 277.45 & 19.548 & 2.737 & 271.95 & 282.95 & 238 & 333 \\
\hline OP & 41 & 299.90 & 41.251 & 5.893 & 288.05 & 311.75 & 202 & 415 \\
\hline CBT & 31 & 318.52 & 41.092 & 7.380 & 303.44 & 333.59 & 216 & 377 \\
\hline Sum & 131 & 295.56 & 37.767 & 3.300 & 289.04 & 302.09 & 202 & 415 \\
\hline
\end{tabular}

In statistics, the Kolmogorov-Smirnov test (Lopes et al., 2007) is a nonparametric test for the equality of continuous, one-dimensional probability distributions that can be implemented to compare a sample with a reference probability distribution, which is used in our survey. The KolmogorovSmirnov statistic quantifies a distance between the empirical distribution function of the sample and the cumulative distribution function of the reference distribution, or between the empirical distribution functions of two sample tests.

The null distribution of this statistic is evaluated under the null hypothesis that the samples are drawn from the same distribution (in the two-sample case) or that the sample is drawn from the reference distribution (in the one-sample case). In each case, the distributions considered under the null hypothesis are continuous distributions but are otherwise unrestricted. Table 2 shows the results of Kolmogorov-Smirnov test in our survey.

Table 2

The results of one-sample Kolmogorov-Smirnov test

\begin{tabular}{cccccc}
\hline & $\mathrm{N}$ & Mean & Standard deviation & Minimum & Maximum \\
\hline EI & 131 & 295.56 & 37.767 & 202 & 415 \\
\hline
\end{tabular}

The results of Table 2 confirm that the data are normally distributed. Next, we need to confirm whether there is a meaningful difference among the variances of three groups. We have used Levene statistics, which yields a number of 9.364 and we couldn't make any conclusion. Therefore, we use ANOVA test to whether there is any difference between the variance of these numbers. Table 3 shows details of our computations. 
Table 3

The ANOVA results

\begin{tabular}{llllll}
\hline & Sum of Squares & df & Mean Square & F & Sig. \\
\hline Between groups & 33983.34 & 2 & 16991.670 & 14.361 & 0.000 \\
Within groups & 151444.9 & 128 & 1183.163 & & \\
\hline Total & 185428.2 & 130 & & & \\
\hline
\end{tabular}

The results of indicate that there is a meaningful difference among the variances of three groups. Now we switch to Tamhane, Dunnett T3 or Games-Howell tests (Hochberg \& Tamhane, 1987) for the judgment of pairwise comparison of the data. The results of Table 4 indicates that there is meaningful difference between the average EI of the people who were in group UI with other two groups of OP and CBT.

Table 4

The results of Tamhane, Dunnett T3 or Games-Howell tests

\begin{tabular}{|c|c|c|c|c|c|c|c|}
\hline & \multirow[b]{2}{*}{ Group I } & \multirow[b]{2}{*}{ Group J } & \multirow[b]{2}{*}{$\begin{array}{c}\text { Mean } \\
\text { difference (I-J) }\end{array}$} & \multirow[b]{2}{*}{$\begin{array}{l}\text { Standard } \\
\text { Error }\end{array}$} & \multirow[b]{2}{*}{ Sig. } & \multicolumn{2}{|c|}{$95 \%$ Confidence level } \\
\hline & & & & & & $\begin{array}{l}\text { Lower } \\
\text { bound }\end{array}$ & $\begin{array}{l}\text { Upper } \\
\text { bound }\end{array}$ \\
\hline \multirow{6}{*}{ Tamhane } & & OP & -22.447 & 6.498 & 0.003 & -38.35 & -6.54 \\
\hline & UI & $\mathrm{CBT}$ & -41.065 & 7.872 & 0.001 & -60.72 & -21.41 \\
\hline & & UI & 22.447 & 6.498 & 0.003 & 6.54 & 38.35 \\
\hline & OP & CBT & -18.618 & 9.445 & 0.151 & -41.77 & 4.54 \\
\hline & & UI & 41.065 & 7.872 & 0.000 & 21.41 & 60.72 \\
\hline & $\mathrm{CBT}$ & $\mathrm{OP}$ & 18.618 & 9.445 & 0.151 & -4.54 & 41.77 \\
\hline \multirow{6}{*}{$\begin{array}{l}\text { Dunnett } \\
\text { T3 }\end{array}$} & & OP & -22.447 & 6.498 & 0.003 & -38.34 & -6.55 \\
\hline & UI & CBT & -41.065 & 7.872 & 0.001 & -60.68 & -21.45 \\
\hline & & UI & 22.447 & 6.498 & 0.003 & 6.55 & 38.34 \\
\hline & OP & CBT & -18.618 & 9.445 & 0.149 & -41.75 & 4.51 \\
\hline & & UI & 41.065 & 6.498 & 0.000 & 21.45 & 60.68 \\
\hline & CBT & OP & 18.618 & 9.445 & 0.149 & -4.51 & 41.75 \\
\hline \multirow{6}{*}{$\begin{array}{l}\text { Games- } \\
\text { Howell }\end{array}$} & & OP & -22.447 & 6.498 & 0.003 & -38.02 & -6.88 \\
\hline & UI & CBT & -41.065 & 7.872 & 0.000 & -60.26 & -21.88 \\
\hline & & UI & 22.447 & 6.498 & 0.003 & 6.88 & 38.02 \\
\hline & OP & $\mathrm{CBT}$ & -18.618 & 9.445 & 0.128 & -41.28 & 4.04 \\
\hline & & UI & 41.065 & 7.872 & 0.000 & 21.88 & 60.26 \\
\hline & CBT & $\mathrm{OP}$ & 18.618 & 9.445 & 0.128 & -4.04 & 41.28 \\
\hline
\end{tabular}

One obvious conclusion from the results of our discussion is that we can definitely increase the chance of reducing the number of addicted people, significantly. There is no doubt that a healthy population could contribute to society, the rates of criminals will be reduced, substantially.

\section{Conclusion}

In this paper, we have presented an empirical study to measure emotional intelligence among different groups of people who were addicted to drugs. The study distributed a questionnaire among three groups consists of 117 questions and 15 scales. The first group of the survey was under community-based treatment, the second group included the people who were members of a community with unknown identification and the third group covered outpatient patient who received medication. The results of our survey indicated the level of emotional intelligence among the first group of our study was much more than the other groups. The impact of EI on outpatient was also more than the other group. However, the difference was not statistically meaningful. We hope the 
present study could help governmental agencies to setup useful regulations to increase communitybased treatments in an attempt to increase EI among patients. Any increase on EI for outpatients seem to be beneficial to help them get rid of drugs.

\section{Acknowledgment}

The author would like to thank Islamic Azad University for their financial support on this project. The author also grateful for constructive comments received from the anonymous referees on earlier version of this working paper.

\section{References}

Besharat, M.A. (2007).Psychometric properties of Farsi version of the Emotional Intelligence Scale41 (FEIS-41). Personality and Individual Differences, 43(5), 991-1000.

Beranuy, M., Oberst, U., Carbonell, X., Chamarro, A. (2009).Problematic Internet and mobile phone use and clinical symptoms in college students: The role of emotional intelligence. Computers in Human Behavior, 25(5), 1182-1187.

Côté, S., Lopes, P.N., Salovey, P., \& Miners, C.T.H. (2010). Emotional intelligence and leadership emergence in small groups. The Leadership Quarterly, 21(3), 496-508.

Hill, E.M., \& Maggi, S. (2011). Emotional intelligence and smoking: Protective and risk factors among Canadian young adults. Personality and Individual Differences, 51(1), 45-50.

Hochberg, Y., \& Tamhane, A.C. (1987). Multiple Comparison Procedures. John Wiley \& Sons.

Joseph, D.L., Newman, D.A. (2010). Emotional Intelligence: An Integrative Meta-Analysis and Cascading Model. Journal of Applied Psychology, 95(1), 54-78.

Khanmohammadi, A., Homayouni, A., Mosavi Amiri, S.J., \& Nikpour, G.A. (2009). P01-43 Low emotional intelligence as a predictor of tendency to addiction. European Psychiatry, 24, S431.

Khatiri Yanesari, M., \& Homayouni, A., \& Gharib, K. (2010). P02-99 - Can emotional intelligence predicts addiction to internet in university students? European Psychiatry, 25(1), 748.

Kilduff, M., Chiaburu, D.S., \& Menges, J.I. (2010). Strategic use of emotional intelligence in organizational settings: Exploring the dark side. Research in Organizational Behavior, 30, 129152.

Lopes, R.H.C., Reid, I., \& Hobson, P.R. (2007). The two-dimensional Kolmogorov-Smirnov test. XI International Workshop on Advanced Computing and Analysis Techniques in Physics Research (April 23-27, 2007) Amsterdam, the Netherlands.

Matthews, G., Emo, A.K., Funke, G., Zeidner, M., Roberts, R.D., Costa Jr., P.T., \& Schulze, R. (2006). Emotional Intelligence, Personality, and Task-Induced Stress. Journal of Experimental Psychology: Applied, 12(2), 96-107.

Parker, J.D.A., Taylor, R.N., Eastabrook, J.M., Schell, S.L., \& Wood, L.M. (2008). Problem gambling in adolescence: Relationships with internet misuse, gaming abuse and emotional intelligence. Personality and Individual Differences, 45(2), 174-180.

Talebzadeh Sani, H., \& Homayouni, A. (2010). P03-262 - A survey on relationship between emotional intelligence and personality traits in addicted people. European Psychiatry, 25(1), 1329.

Trinidad, D.R., \& Johnson, C.A. (2002). The association between emotional intelligence and early adolescent tobacco and alcohol use. Personality and Individual Differences, 32(1), 95-105.

Schutte, N.S., \& Malouff, J.M. (2011).Emotional intelligence mediates the relationship between mindfulness and subjective well-being. Personality and Individual Differences, 50(7), 1116-1119.

de Sousa Uva, M.C., de Timary, P., Cortesi, M., Mikolajczak, M., du Roy de Blicquy, P., Luminet, O. (2010). Moderating effect of emotional intelligence on the role of negative affect in the motivation to drink in alcohol-dependent subjects undergoing protracted withdrawal. Personality and Individual Differences, 48(1), 16-21. 
Song, L.J., Huang, G.H., Peng, K.Z., Law, K.S., Wong, C.S., \& Chen, Z. (2010). The differential effects of general mental ability and emotional intelligence on academic performance and social interactions. Intelligence, 36(1), 137-143.

Williams, C., Daley, D., Burnside, E., \& Hammond-Rowley, S. (2009). Measuring emotional intelligence in preadolescence. Personality and Individual Differences, 47(4), 316-320. 